\title{
Pulmonary artery pressure in thoracic scoliosis during and after exercise while breathing air and
} pure oxygen

\section{J M SHNEERSON}

From the Cardiothoracic Institute, Brompton Hospital, London, UK

Shneerson, J M (1978). Thorax, 33, 747-754. Pulmonray artery pressure in thoracic scoliosis during and after exercise while breathing air and pure oxygen. Pulmonary artery catheterisation was carried out in 25 scoliotics aged 13 to 67 years (mean 30.7). Each then performed a progressive exercise test breathing air, and 11 performed a similar test breathing pure oxygen.

The mean pulmonary artery pressure (PAP) increased linearly with oxygen uptake $\left(\dot{\mathrm{V}}_{2}\right)$ and with the work rate. The pressure responses have been described in terms of their intercept and

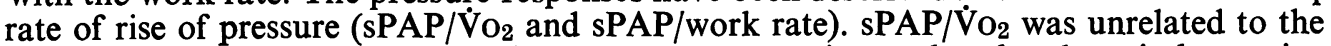
anatomical features of the scoliosis, or to $\mathrm{PaO}_{2}$. It was inversely related to vital capacity, functional residual capacity, and total lung capacity. Inspiration of pure oxygen lowered the resting pressure by a mean of $3.2 \mathrm{mmHg}$ but only decreased SPAP/work rate by $9 \%$. The maximum pressure reached during exercise was diminished by a mean of $5.2 \mathrm{mmHg}$ when pure oxygen was breathed.

The mean pressures were shown to fall exponentially after exercise. The time constants were proportional to sPAP/ $/ \mathrm{VO}_{2}$ and to the final pressure reached during exercise. Inspiration of pure oxygen did not affect the time constants but decreased the post-exercise pressure load by lowering the final pressure during exercise.

Right ventricular hypertrophy in scoliotics was first observed by Corvisart (1806) and Harrison (1820), who attributed it to the distortion of the large arteries. Bachmann (1899) detected it in $82 \%$ of 197 necropsies in kyphoscoliotics. Barié (1904) was the first to attribute it to pulmonary hypertension. The demonstration of this was delayed until the advent of cardiac catheterisation for clinical use (Schaub et al, 1954). Soon afterwards Bergofsky et al (1959) showed that the cardiac output and pulmonary wedge pressures were normal. The right ventricular hypertrophy of the scoliotic is thus analogous to the cor pulmonale of respiratory diseases. Shneerson et al (1977) have shown that the mean pulmonary artery pressure at rest is inversely related to the arterial $\mathrm{Po}_{2}$, but there have been no adequate studies of the pulmonary artery pressure during exercise.

In the present study the mean pulmonary artery pressure has been studied both during and after a standardised progressive exercise test. The effects of inspiring pure oxygen have been recorded.

\section{Methods}

Twenty-five subjects (11 male, 14 female) with thoracic scoliosis gave informed consent to be studied. Their ages ranged from 13 to 67 years (mean $=30 \cdot 7, \mathrm{SD}=12 \cdot 7$ ). The scoliosis was congenital in five, idiopathic in seven, due to poliomyelitis or other neurological disease in eight, and associated with Marfan's syndrome in two and neurofibromatosis in three. The age of onset, side, and level of the scoliosis were also noted. Thirteen had previously undergone spinal fusion. One subject had mild chronic obstructive bronchitis, but none of the others had any respiratory or cardiac disease complicating the scoliosis. The angle of scoliosis was measured by the method of Cobb (1948). The functional residual capacity (FRC) inspiratory capacity (IC), vital capacity (VC), and total lung capacity (TLC) were determined in a constant volume whole body plethysmograph (DuBois et al, 1956).

A saline-filled nylon catheter $1 \mathrm{~mm}$ external 
diameter (Bradley, 1964) was passed into the pulmonary artery. No sedation was required. The catheter was connected to a Consolidated Electrodynamics strain-gauge manometer (Type 4-326L212) and thence to an amplifier, oscilloscope, and direct-writing ink-jet recorder (Mingograf 81). The response of the system was linear to 12 Herz. Both undamped and mean pressure tracings were recorded, but only the latter were used in the subsequent analyses. The zero reference level was taken as the level of the fourth costosternal junction. Pulmonary artery pressures were recorded before, during, and after exercise. A continuous ECG trace was displayed on the oscilloscope. An arterial cannula was used to obtain blood samples for gas analysis.

Exercise was performed while sitting on an electrically braked bicycle ergometer (Lode). The inspiratory minute volume was measured by a Parkinson Cowan CD4 dry gas meter with an electrical output to the Mingograf. The gas meter was calibrated with a sinusoidal electric pump operating at various stroke volumes and frequencies. The gas meter was connected by widebore tubing to a low resistance two-way respiratory valve (P K Morgan 71522) with a dead space of $60 \mathrm{ml}$. The expired gas passed through widebore connecting tubing to a mixing chamber of 7.8 1 containing an electrically-driven fan. A sample of the mixed expired gas was dried with magnesium perchlorate and passed in series through a paramagnetic Servomex OA 150 oxygen analyser and an infrared absorption $\mathrm{CO}_{2}$ analyser (URAS 4). The oxygen analyser was linear over the range $14-21 \% \mathrm{O}_{2}$. The $95 \%$ response times of both to a square wave of gas leaving the mixing chamber were four seconds. Both machines were connected electrically to the recorder and were recalibrated before and after each test.

The patients were familiarised with the apparatus on the day before the tests. They rested on the ergometer until their inspired ventilation, mixed expired gas composition, and heart rate were steady. They then began pedalling, initially at a work rate of 15 watts. The work rate was increased each minute by 15 watts until the patient was forced to stop through breathlessness or tiredness. Observations were made at rest, at the end of each minute during exercise, and at the end of each minute after exercise. Eleven subjects repeated the test while breathing $100 \% \mathrm{O}_{2}$ without $\mathrm{VO}_{2}$ being measured.

The mean readings of $\mathrm{F}_{\mathrm{EO}}$ over the last 15 seconds and the $\mathrm{VE}$ over the last 30 seconds of each minute were used to calculate $\mathrm{Vo}_{2}$. Regression lines were drawn using the least squares method, and the significance of the results was tested with Student's $t$ test.

\section{Results}

RESTING PA PRESSURE

The PA mean pressure at rest ranged from $10-51 \mathrm{mmHg}(1 \cdot 33-6.80 \mathrm{kPa})(\mathrm{n}=25$, mean $=$ $19.8 \mathrm{mmHg}(2.64 \mathrm{kPa}), \mathrm{SD}=9.5 \mathrm{mmHg}(1.27 \mathrm{kPa}))$. The pressure was $20 \mathrm{mmHg}$ or more in eight subjects $(32 \%)$. In the 11 who exercised while breathing pure oxygen the mean resting pressure on oxygen was $19.1 \mathrm{mmHg}(2.55 \mathrm{kPa})(\mathrm{SD}=$ $7.2 \mathrm{mmHg}(0.96 \mathrm{kPa}))$ compared with a mean pressure of $22.3 \mathrm{mmHg}(2.97 \mathrm{kPa})(\mathrm{SD}=9.7 \mathrm{mmHg}$ $(1.29 \mathrm{kPa}))$ while breathing air.

\section{MAXIMUM PA PRESSURE DURING EXERCISE}

The highest mean PA pressure reached during exercise breathing air ranged from $16-75 \mathrm{mmHg}$ $(2 \cdot 13-10.00 \mathrm{kPa}) \quad(\mathrm{n}=25, \quad$ mean $=35.8 \mathrm{mmHg}$ $(4.77 \mathrm{kPa}), \mathrm{SD}=13.6 \mathrm{mmHg}(1.81 \mathrm{kPa}))$. The pressure reached $30 \mathrm{mmHg}(4.00 \mathrm{kPa})$ in 17 $(68 \%)$ and $40 \mathrm{mmHg}(5.33 \mathrm{kPa})$ in nine $(36 \%)$ subjects. In the 11 who performed both exercise tests, the mean maximum PA pressure was $42.9 \mathrm{mmHg} \quad(5.72 \mathrm{kPa}) \quad(\mathrm{SD}=13.5 \quad \mathrm{mmHg}$ $(1.80 \mathrm{kPa})$ ) while breathing air and $37.7 \mathrm{mmHg}$ $(5.03 \mathrm{kPa})(\mathrm{SD}=10.2 \mathrm{mmHg}(1.36 \mathrm{kPa}))$ while breathing pure oxygen.

\section{PATTERN OF PA PRESSURE RESPONSE DURING}

EXERCISE

The mean pressure rose rapidly at the start of each minute at a higher work load and was almost steady for the last 30 seconds of each minute. The pressures recorded at the end of each minute increased linearly with the $\mathrm{Vo}_{2}$ and the work rate (fig 1). The pressure response can therefore be described by the equation:

$$
\text { mean PA pressure }=\mathrm{sVO}_{2}+\mathrm{c}
$$

where $s$ is the slope of the relationship between PA pressure and $\mathrm{Vo}_{2}$ (ie $\mathrm{sPAP} / \mathrm{Vo}_{2}$ ) and $\mathrm{c}$ is the $\mathrm{N}$ intercept on the $y$ axis.

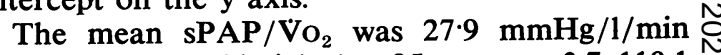
$(0.083 \mathrm{kPa} / \mathrm{mmol} / \mathrm{min})(\mathrm{n}=25$, range $=3.7-110 \cdot 1 \mathrm{\omega}$ $\mathrm{mmHg} / 1 / \mathrm{min}(0.011-0.328 \mathrm{kPa} / \mathrm{mmol} / \mathrm{min}), \mathrm{SD}=$ ? $26.2 \mathrm{mmHg} / \mathrm{l} / \mathrm{min}(0.078 \mathrm{kPa} / \mathrm{mmol} / \mathrm{min}))$. This is significantly in excess $(P<0.001)$ of the $\Phi$ normal value for untrained adults of $6.5 \mathrm{mmHg} / \stackrel{\text { ? }}{?}$ $1 / \mathrm{min}(0.019 \mathrm{kPa} / \mathrm{mmol} / \mathrm{min}) \quad\left(\mathrm{n}=16, \quad \mathrm{SD}=3.5 \frac{7}{0}\right.$ $\mathrm{mmHg} / 1 / \mathrm{min} \quad(0.010 \mathrm{kPa} / \mathrm{mmol} / \mathrm{min}))$, recal- $\frac{0}{\mathbb{D}}$ culated from the data of Bevegard et al $(1960 ; \stackrel{\odot}{\odot}$

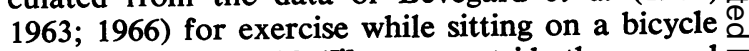
ergometer. The sPAP/ $/ \mathrm{Vo}_{2}$ was outside the normalo range in 19 out of the 25 subjects $(76 \%)$. 


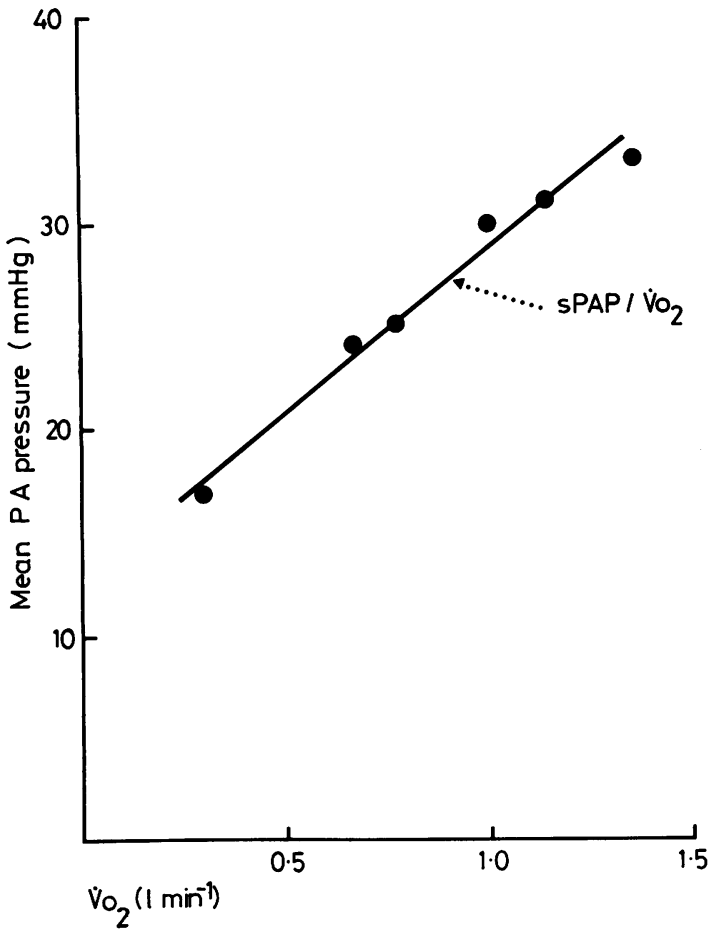

Fig 1 Relationship between mean PAP and $\mathrm{VO}_{2}$ in a typical subject.

$\mathrm{sPAP} / \mathrm{Vo}_{2}$ was inversely correlated with $\mathrm{VC}$, FRC, and TLC (fig 2). The hyperbolic relationship for all three volumes is confirmed by the linear correlation between the reciprocal of $\mathrm{SPAP} / \mathrm{VO}_{2}$ (that is $\mathrm{SVO}_{2} / \mathrm{PAP}$ ) and VC, FRC, and TLC (fig 3). The patient with chronic bronchitis and one other with polymyositis were excluded from these analyses.

The sPAP/ $/ \mathrm{Vo}_{2}$ was unrelated to the age or sex of the subjects, the aetiology of the deformity, age at onset, the side or level of the scoliosis, the angle of scoliosis, and whether or not a spinal fusion had been performed.

The $\mathrm{PaO}_{2}$ ranged from $38 \cdot 0-100.5 \mathrm{mmHg}(5.07-$ $13.40 \mathrm{kPa})(\mathrm{n}=12$, mean $=73.8 \mathrm{mmHg}(9.84 \mathrm{kPa})$, $\mathrm{SD}=16.7 \mathrm{mmHg}(2.23 \mathrm{kPa}))$ before exercise and from $39.5-99.8 \mathrm{mmHg}(5 \cdot 27-13.31 \mathrm{kPa})$ (mean $=$ $76.0 \mathrm{mmHg} \quad(10.13 \mathrm{kPa}), \quad \mathrm{SD}=18.3 \mathrm{mmHg}$ $(2.44 \mathrm{kPa}))$ immediately after exercise. There was no correlation, however, between $\mathrm{SPAP} / \mathrm{VO}_{2}$ and $\mathrm{PaO}_{2}$ at the end of exercise, the change of $\mathrm{PaO}_{2}$ during exercise, or to the drop in $\mathrm{pH}$ during exercise or the $\mathrm{PaCO}_{2}$ at the end of exercise.

The responses during the exercise tests breathing air and oxygen can be compared by examining the SPAP/work rate (fig 4). The values in the two tests were closely linked (fig 5). The regression coefficient of the relationship was $1 \cdot 10$, indicating that inspiring pure oxygen only decreased SPAP/ work rate by about $9 \%$.

The intercept (c) of the relationship between PA pressure and $\mathrm{Vo}_{2}$ ranged from $2.2-24.7 \mathrm{mmHg}$ $(0.29-3.29 \mathrm{kPa}) \quad(\mathrm{n}=25$, mean $=11 \cdot 1 \mathrm{mmHg}$ $(1.48 \mathrm{kPa}), \mathrm{SD}=5.0 \mathrm{mmHg}(0.67 \mathrm{kPa}))$. It was not significantly higher in those whose $\mathrm{SPAP} / \mathrm{Vo}_{2}$

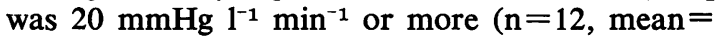
$12.4 \mathrm{mmHg}(1.65 \mathrm{kPa}), \mathrm{SD}=6.0 \mathrm{mmHg}(0.80 \mathrm{kPa}))$ than in the subjects with a slower rise of pressure $(\mathrm{n}=13$, mean $=10.7 \mathrm{mmHg}(1.43 \mathrm{kPa}), \mathrm{SD}=$ $3.2 \mathrm{mmHg}(0.43 \mathrm{kPa}))$.

PA PRESSURE CHANGES AFTER EXERCISE

After exercise pulmonary artery pressure fell rapidly at first and then more slowly towards the pre-exercise level (fig 6). Semi-logarithmic plots showed that the fall was exponential. The time constants after the test breathing air were closely correlated with $\mathrm{sPAP} / \mathrm{Vo}_{2} \quad(\mathrm{n}=13, \mathrm{r}=0.899$ $P<0.001)$ and the final PA pressure attained during the test $(n=13, r=0.877, P<0.001)$. They were not significantly different after the two tests (airmean time constant $=84.5 \mathrm{~s}$, SEM $17.6 \mathrm{~s}$; oxygen mean time constant $=105 \cdot 2 \mathrm{~s}, \mathrm{SEM}=22 \cdot 3 \mathrm{~s}$ ).

\section{Discussion}

Eight of the 25 subjects (32\%) had pulmonary hypertension at rest, defined as a mean pressure of $20 \mathrm{mmHg}$ or more. The inspiration of pure oxygen lowered the resting pressure in 10 out of the 11 subjects who performed both exercise tests. The mean fall in pressure, however, was only $3.2 \mathrm{mmHg}(0.43 \mathrm{kPa})$.

The rise of mean pulmonary artery pressure during exercise has been found to be linearly related to the oxygen consumption and to the work rate achieved. This has enabled the pressure response to be described in terms of its intercept (c) and rate of rise (sPAP/Vo $/ \mathrm{O}_{2} ; \mathrm{sPAP} /$ work rate). This is preferable to the use of the maximum pressure achieved as this depends on the motivation of the subject to keep exercising to his physical limit, and also varies according to the exercise capacity of the individual. The mean pressure at a specified ${\nabla o_{2}}_{2}$, such as $1.01 \mathrm{~min}^{-1}$, is a better index than the maximum pressure. It does not differentiate, however, between the effects of the individual components (intercept and slope) of the pressure and, in addition, the most severely affected subjects were unable to exercise to a sufficiently great $\mathrm{Vo}_{2}$. 

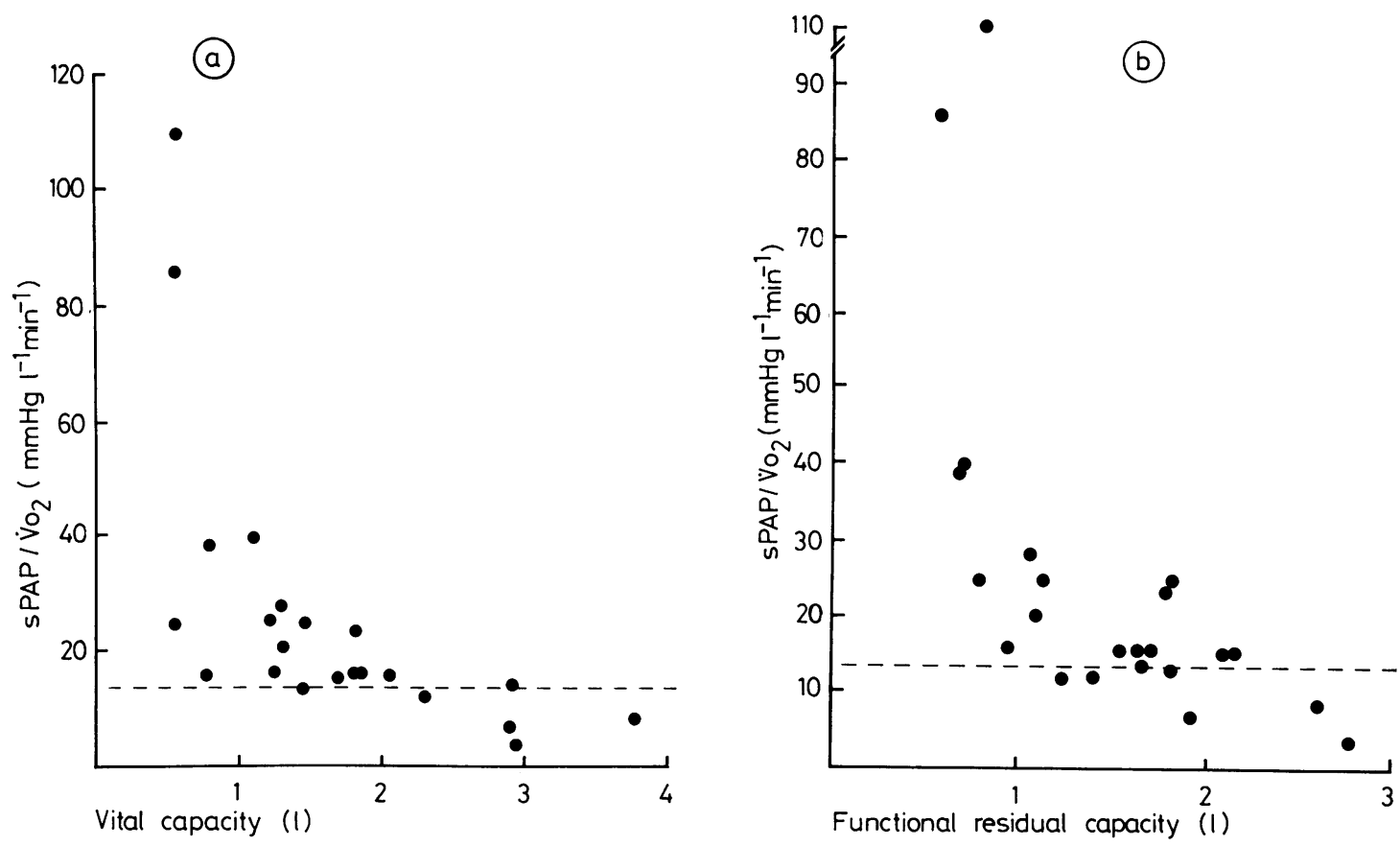

के

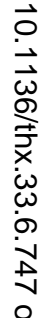

Functional residual capacity (I)

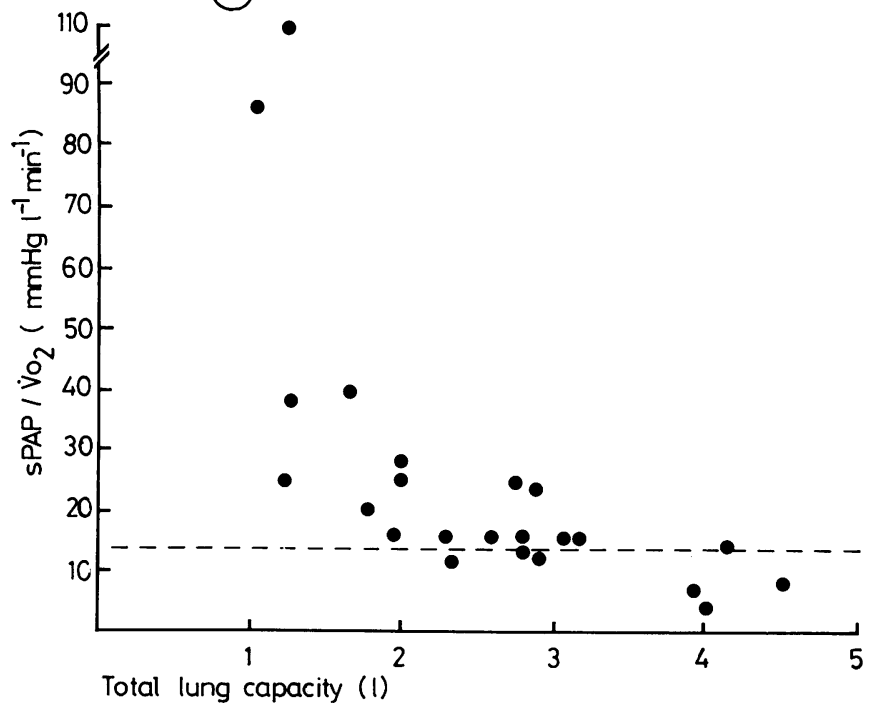

Fig 2 Relationship between $S P A P / \dot{V}_{2}$ and (a) VC, (b) FRC, and (c) TLC. 

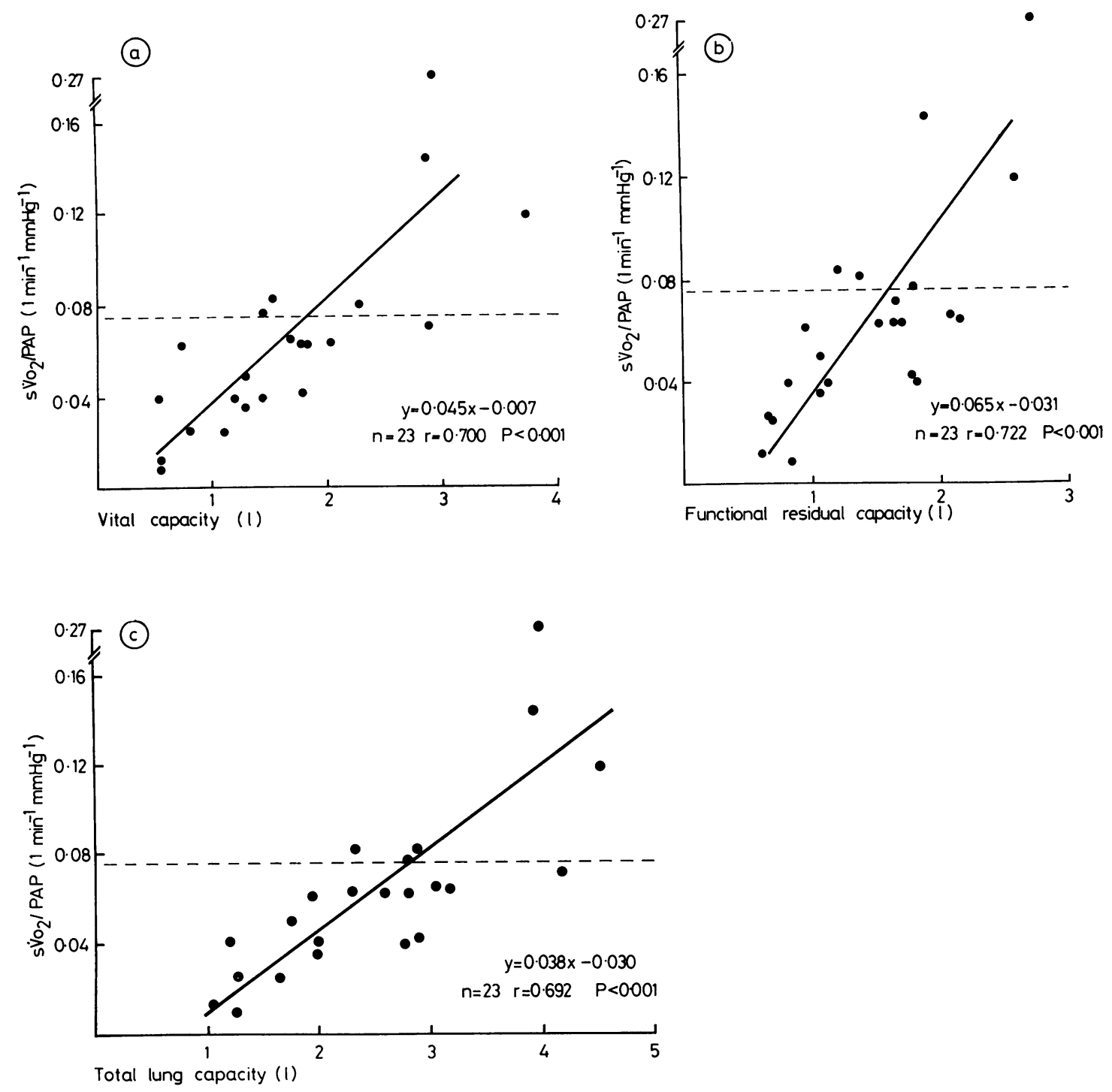

Fig 3 Relationship between $s \dot{V}_{2} / P A P$ and (a) VC, (b) FRC, and (c) TLC. 


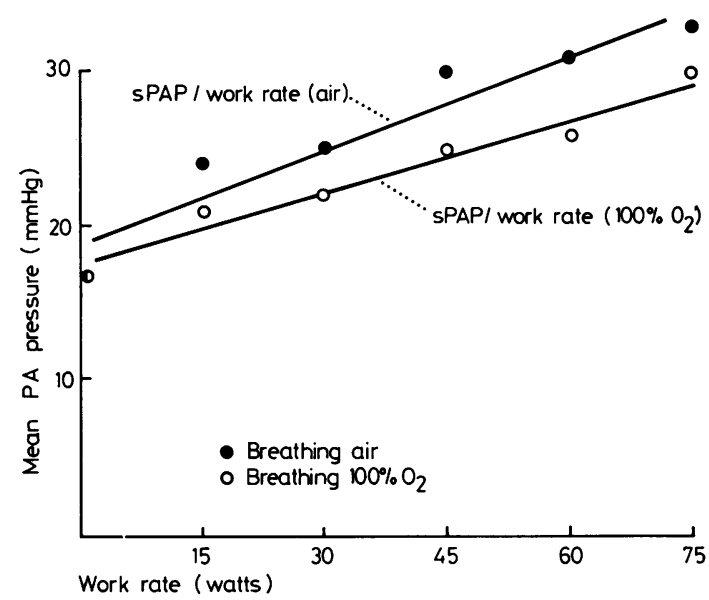

Fig 4 sPAP/work rate while breathing air and $100 \%$ oxygen in a typical subject.

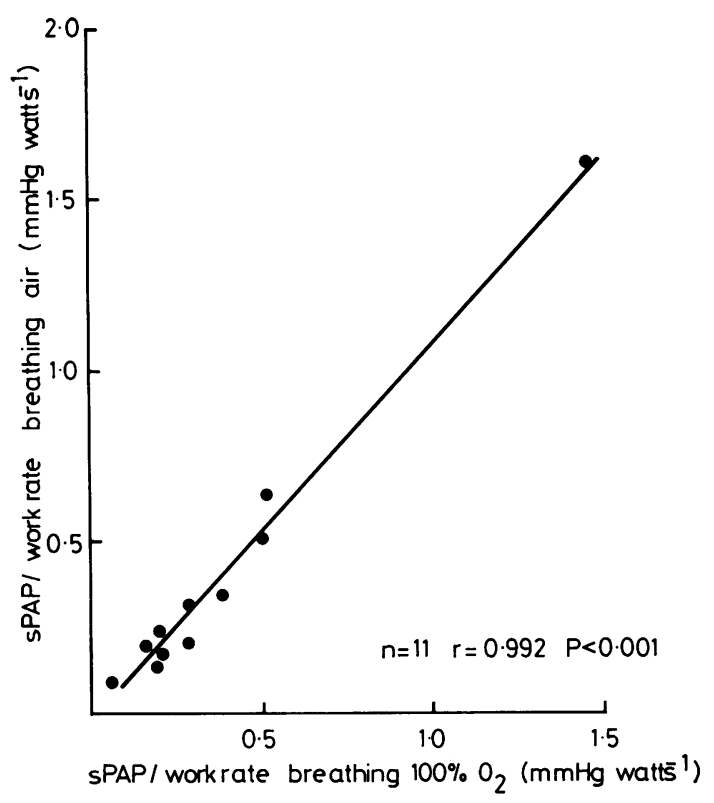

Fig 5 Correlation between $S P A P /$ work rate during exercise breathing air and $100 \%$ oxygen.

The physiological significance of $\mathrm{sPAP} / \mathrm{Vo}_{2}$ is that it is a measure of the pulmonary vascular resistance if $\mathrm{Vo}_{2}$ is proportional to the cardiac output and if the left atrial pressure remains constant during exercise. These assumptions were shown to be valid in scoliotics by Bergofsky et al (1959).

In the present study $\mathrm{SPAP} / \mathrm{Vo}_{2}$ was above the normal range in $76 \%$ of the subjects (Bevegård

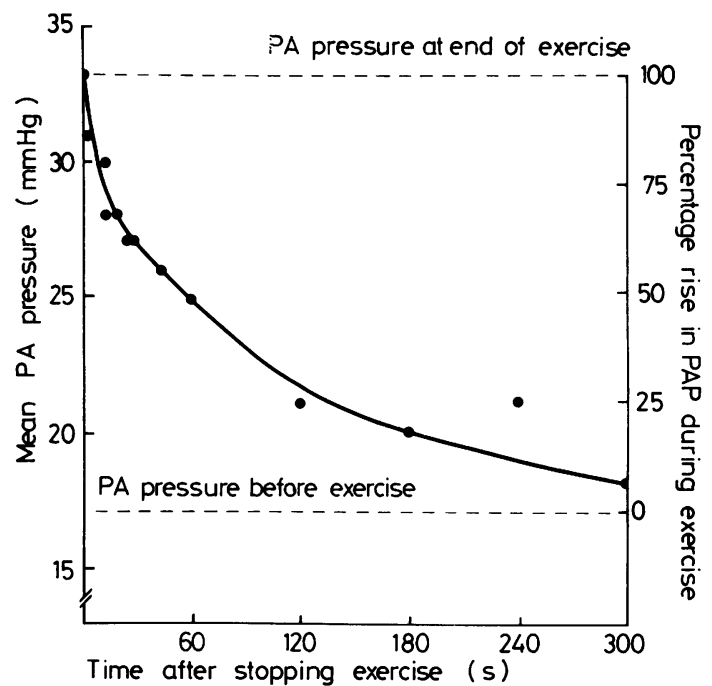

Fig 6 Exponential fall in PA pressure after exercise in a typical subject.

et al, 1960; 1963; 1966), although there was a wide scatter of values. Nevertheless, when these were plotted against the volume of the lungs, expressed as VC, FRC, or TLC, an inverse hyperbolic relationship appeared (fig 2). The reciprocal of sPAP/ $/ \mathrm{Vo}_{2}$ (that is $\mathrm{sVo}{ }_{2} / \mathrm{PAP}$ ) was linearly related to all three volumes and, conceptually, approximates to the pulmonary vascular conductance. VC was chosen to represent lung size as it is the most convenient volume to measure, FRC because it is about the lung volume at which these patients were breathing during exercise, and TLC because it is the maximum size of the lungs attainable physiologically. The correlations were similar with all three lung volumes.

The rate of rise of pressure during exercise increases after pneumonectomy (Cournand et al, 1950) and after balloon-occlusion of one pulmonary artery (Emirgil et al, 1967). In both conditions the volume of perfused lung is de- $\widetilde{N}$ creased, but the lung tissue itself is almost normal. This is also true of the scoliotic (Dunnill, 1965).

The sPAP $/ \mathrm{Vo}_{2}$ breathing air was independent $\mathrm{\omega}$ of the arterial $\mathrm{Po}_{2}$ immediately after exercise and its change during exercise. This contrasts with $\mathscr{C}$ the inverse relationship between pulmonary artery pressure at rest and the $\mathrm{Po}_{2}$ in scoliotics (Shneerson et al, 1977) and chronic lung diseases such as chronic bronchitis and emphysema (Whitaker, 1954) and tuberculosis (Söderholm, 1959). In addition, the inspiration of pure oxygen only $\stackrel{\mathbb{Q}}{\varrho}$ diminished sPAP/work rate by $9 \%$. Presumably any vasoconstrictor effect of hypoxaemia is 
quantitatively much less important than the anatomical restriction of the pulmonary vascular bed (associated with the small size of the lungs) in determining the pulmonary vascular resistance. It might be expected that in other lung diseases, such as chronic bronchitis, characterised by more severe hypoxia but less diminution of the pulmonary vascular bed, the effect of hypoxaemia would be more apparent.

The intercept (c) ranged from $2 \cdot 2$ to $24.7 \mathrm{mmHg}$ but did not correlate with $\mathrm{SPAP} / \mathrm{Vo}_{2}$. Inspiration of pure oxygen tended to decrease the intercept by lowering the resting pressure but to increase it by flattening the regression line between PA pressure and work rate.

The maximum pressure attained during exercise varied considerably, since it is determined by $\mathrm{Vo}_{2}$ max as well as the intercept and $\mathbf{s P A P} / \mathrm{Vo}_{2}$. In the 11 subjects who performed both exercise tests the maximum PA pressure was lowered by a mean of $5.2 \mathrm{mmHg}$ when pure oxygen was inspired.

The time-course of the fall in PA pressure after exercise has been examined in more detail than in any previous study. No data for scoliotics are available at all in published reports. Slonim et al (1954) observed that in normal subjects the pressure approached the pre-exercise level within two minutes of stopping exercise, and that the rate of fall was most rapid initially. The fall was exponential in these scoliotics, and this has enabled the rate of fall to be expressed as the time constant. In this way comparison between individual patients and between the two exercise tests can be made.

The time constants after the test breathing air were closely correlated with $\mathrm{sPAP} / \mathrm{Vo}_{2}$ and the final PA pressure achieved during the test. Thus the more severe the pulmonary hypertension during exercise, the greater the pressure load on the right ventricle after exercise. In everyday life this "post-exercise hypertension" may be an important, but hitherto neglected, element in determining the extent of right ventricular hypertrophy.

Inspiration of pure oxygen did not significantly influence the time constant of the pressure decay. This is not unexpected since oxygen has only a minor effect on the main haemodynamic change immediately after exercise-the fall in cardiac output. Adequate oxygenation, however, does decrease post-exercise hypertension by decreasing the PA pressure at the end of exercise via its two effects of lowering the resting pressure and the rate of rise of pressure.

I thank Dr F J Prime for his advice, Dr P A
Zorab for allowing me to study his patients, $\mathrm{Mr}$ R Madgwick for technical help, and Mrs J L MacGuigan for the typing.

I am also grateful to the Research Committee of the Brompton Hospital and to Boehringer Ingelheim Ltd for financial support.

\section{References}

Bachmann, M (1899). Die Veränderungen der inneren Organe bei hochgradigen Skoliosen und Kyphoskoliosen. (Bibliotheca Medica. Abt, D ${ }^{1}$. Heft 4.) Stuttgart, Nägele.

Barié, M E (1904). Le coeur dans les déviations du rachis et dans les déformations thoraciques. $L a$ Semaine Médicale, 24, 65-67.

Bergofsky, E H, Turino, G M, and Fishman, A P (1959). Cardiorespiratory failure in kyphoscoliosis. Medicine, 38, 263-317.

Bevegård, S, Freyschuss, U, and Strandell, T (1966). Circulatory adaptation to arm and leg exercise in supine and sitting position. Journal of Applied Physiology, 21, 37-46.

Bevegård, S, Holmgren, A, and Jonsson, B (1960). The effect of body position on the circulation at rest and during exercise, with special reference to the influence on stroke volume. Acta Physiologica Scandinavica, 49, 279-298.

Bevegård, S, Holmgren, A, and Jonsson, B (1963). Circulatory studies in well trained athletes at rest and during heavy exercise, with special reference to stroke volume and the influence of body position. Acta Physiologica Scandinavica, 57, 26-50.

Bradley, R D (1964). Diagnostic right-heart catheterization with miniature catheters in severely ill patients. Lancet, 2, 941-942.

Cobb, J R (1948). Outline for the study of scoliosis. In Instructional Course Lectures. American Academy of Orthopaedic Surgeons, 5, 261-275.

Corvisart, J N (1806). Essai sur les Maladies et les Lésions Organiques du Coeur et des Gros Vaisseaux; Extrait des Leçons Cliniques, pp. 114-117. Migneret, Paris.

Cournand, A, Riley, R L, Himmelstein, A, and Austrian, R (1950). Pulmonary circulation and alveolar ventilation-perfusion relationships after pneumonectomy. Journal of Thoracic Surgery, 19, $80-116$.

DuBois, A B, Botelho, S Y, Bedell, G N, Marshall, R, and Comroe, J H, jun (1956). A rapid plethysmographic method for measuring thoracic gas volume: a comparison with a nitrogen washout method for measuring functional residual capacity in normal subjects. Journal of Clinical Investigation, 35, 322326.

Dunnill, M S (1965). Quantitative observations on the anatomy of chronic non-specific lung disease. Medicina Thoracalis, 22, 261-274.

Emirgil, C, Sobol, B J, Campodonico, S, Herbert, W H, and Mechkati, R (1967). Pulmonary circulation in the aged. Journal of Applied Physiology, 23, 631-640. 
Harrison, E (1820). Remarks upon the different appearances of the back, breast, and ribs in persons affected with spinal diseases; and on the effects of spinal distortion on the sanguineous circulation. London Medical and Physical Journal, 44, 365-378.

Schaub, F, Bühlmann, A, Kalin, R, and Wegmann, $T$ (1954). Zur Klinik und Pathogenese des sogenannten Kyphoskolioseherzens. Schweizerische Medizinische Wochenschrift, 84, 1147-1150.

Shneerson, J M, Venco, A, and Prime, F J (1977). A study of the pulmonary artery pressure, electrocardiography, and mechanocardiography in thoracic scoliosis. Thorax, 32, 700-705.

Slonim, N B, Ravin, A, Balchum, O J, and Dressler, $S H$ (1954). The effect of mild exercise in the supine position on the pulmonary arterial pressure of five normal human subjects. Journal of Clinical Investigation, 33, 1022-1030.

Söderholm, B (1959). The pulmonary blood flow in pulmonary tuberculosis and the effect of unilateral occlusion of the pulmonary artery. In Pulmonary Circulation. An International Symposium, 1958. Edited by W R Adams and I Veith, pp 139-146. Grune and Stratton, New York.

Whitaker, W (1954). Pulmonary hypertension in congestive heart failure complicating chronic lung disease. Quarterly Journal of Medicine, 23, 57-72.

Requests for reprints to: Dr J M Shneerson, Westminster Hospital, London SW1. 